\title{
Management of Clevudine-Resistant Chronic Hepatitis B: A Multicenter Cohort Study
}

Eun Young $\mathrm{Cho}^{1}$, Hyung Joon Yim², Young Kul Jung², Sang Jun Suh², Yeon Seok Seo ${ }^{3}$, Ji Hoon Kim ${ }^{3}$, Hong Soo Kim ${ }^{4}$, Sae Hwan Lee ${ }^{4}$, Sang Hoon Ahn ${ }^{5}$, Jeong II Lee ${ }^{5}$, Sook-Hyang Jeong ${ }^{6}$, Jin-Wook Kim ${ }^{6}$, Jin-Woo Lee ${ }^{7}$, In Hee Kim ${ }^{8}$, Hyoung Su $\mathrm{Kim}^{9}$, Sang Jong Park ${ }^{10}$, Jeong Mi Lee ${ }^{11}$, and Seong Gyu Hwang ${ }^{12}$; on behalf of Antiviral Resistance Study Group

${ }^{1}$ Department of Internal Medicine, Wonkwang University School of Medicine, Iksan, ${ }^{2}$ Department of Internal Medicine, Korea University Ansan Hospital, Korea University College of Medicine, Ansan, ${ }^{3}$ Department of Internal Medicine, Korea University College of Medicine, Seoul, ${ }^{4}$ Department of Internal Medicine, Soonchunhyang University College of Medicine, Cheonan, ${ }^{5}$ Department of Internal Medicine, Yonsei University College of Medicine, Seoul, ${ }^{6}$ Department of Internal Medicine, Seoul National University College of Medicine, Seongnam, ${ }^{7}$ Department of Internal Medicine, Inha University School of Medicine, Incheon, ${ }^{8}$ Department of Internal Medicine, Chonbuk National University Medical School, Jeonju, ${ }^{9}$ Department of Internal Medicine, Hallym University College of Medicine, Seoul, ${ }^{10}$ Bundang Jesaeng Hospital, Seongnam, ${ }^{11}$ Department of Public Health, Wonkwang University Graduate School, Iksan, and ${ }^{12}$ Department of Internal Medicine, CHA Bundang Medical Center, CHA University School of Medicine, Seongnam, Korea

Background/Aims: Data are lacking regarding the management of chronic hepatitis $\mathrm{B}(\mathrm{CHB})$ with resistance to clevudine (CLV). This study evaluated the efficacy of different rescue therapies for CLV-resistant CHB. Methods: Patients with CLV-resistant CHB were enrolled in the cohort, and all patients developed virologic breakthrough during CLV therapy and had confirmed-genotypic resistance to CLV (rtM204I mutation) before enrollment. Results: Of the 107 patients, 12 received adefovir (ADV), 21 received a CLV plus ADV combination (CLV+ADV), 34 received a lamivudine plus ADV combination (LAM+ADV), and 40 received entecavir (ETV) therapy for 48 weeks. The CLV+ADV group had the lowest hepatitis $B$ virus (HBV) DNA level $(p<0.0001)$ and showed the greatest reduction of HBV DNA levels from baseline compared to all other groups $(p=0.004)$ at week 48 . HBV DNA was undetectable $(<70 \mathrm{IU} / \mathrm{mL})$ in $0 \%, 57.1 \%, 21.2 \%$, and $27.5 \%(p=0.003)$ of the patients in each group, respectively, at week 48 . At the end of the study, the mean alanine transaminase (ALT) level, rate of ALT normalization, and rate of hepatitis $B$ envelope antigen loss or seroconversion did not differ between groups. Conclusions: CLV+ADV combination therapy in patients with CLV-resistant CHB more effectively suppresses HBV replication than ETV, ADV, or LAM+ADV therapy. (Gut Liver 2017;11:129-135)

Key Words: Clevudine; Resistance; Hepatitis B, chronic; Therapy

\section{INTRODUCTION}

Clevudine (CLV) is a potent antiviral drug approved for chronic hepatitis B (CHB) treatment in several Asian countries. The initial efficacy of CLV has been demonstrated in 12-week and 24-week clinical studies, ${ }^{1-4}$ and the antiviral effect persists even after the drug is stopped, which indicates the drug's unique advantage in terms of relative low viral rebound. ${ }^{1,3} \mathrm{~A}$ 48-week clinical trial of CLV therapy revealed a potent antiviral effect, evidenced by hepatitis B virus (HBV) DNA clearance rates of 76.6\% for the hepatitis B e antigen (HBeAg) positive group, and 96.3\% for the HBeAg negative group; alanine transaminase (ALT) normalization rates were 85\% and 81\% in these respective groups. ${ }^{5,6}$ However, CLV-resistance can develop with longterm treatment. Previous studies have reported CLV-resistance in $2 \%$ to $14 \%$ of patients with no history of lamivudine (LAM) exposure, and in about $40 \%$ of patients with a history of LAM treatment, after 1 year of CLV therapy.

Although CLV has been used in Korea for several years, data are still lacking regarding proper management of CHB with resistance to this drug. In CLV-resistant CHB patients, several experts and guidelines recommend using the same strategies as for resistance to LAM although this suggestion is not based on sufficient clinical evidence. ${ }^{8-10}$ Systematically collected clinical data are necessary to support such guidelines.

Various rescue therapies have been used for CLV-resistant

Correspondence to: Hyung Joon Yim ${ }^{\mathrm{a}}$ and Seong Gyu Hwang ${ }^{\mathrm{b}}$

${ }^{a}$ Department of Internal Medicine, Korea University Ansan Hospital, 123 Jeokgeum-ro, Danwon-gu, Ansan 15355, Korea

Tel: +82-31-412-6565, Fax: +82-31-412-5582, E-mail: gudwns21@korea.ac.kr

${ }^{\mathrm{b}}$ Department of Internal Medicine, CHA Bundang Medical Center, 59 Yatap-ro, Bundang-gu, Seongnam 13496, Korea

Tel: +82-31-780-5213, Fax: +82-2-780-5246, E-mail: gudwns21@korea.ac.kr

Received on November 25, 2015. Revised on January 24, 2016. Accepted on March 22, 2016. Published online August 19, 2016

pISSN 1976-2283 eISSN 2005-1212 https://doi.org/10.5009/gnl15597

() This is an Open Access article distributed under the terms of the Creative Commons Attribution Non-Commercial License (http://creativecommons.org/licenses/by-nc/4.0) which permits unrestricted non-commercial use, distribution, and reproduction in any medium, provided the original work is properly cited. 
CHB patients in Korea before tenofovir (TDF) became available. These include adefovir (ADV) monotherapy, CLV+ADV combination therapy, LAM+ADV combination therapy, and entecavir (ETV) monotherapy. Even in the era of TDF, one of these regimens may need to be administered in patients who are intolerable to TDF. The aim of this multicenter study was to compare the efficacy of these rescue therapies in response to CLV-resistance.

\section{MATERIALS AND METHODS}

\section{Patients}

This cohort study was conducted in 12 hospitals in South Korea between May 2008 and November 2011. Eligible patients were identified according to the following inclusion criteria: age over 18 years, $\mathrm{HBeAg}$ positive or negative $\mathrm{CHB}$, more than 6 months of CLV therapy, development of virologic breakthrough during CLV therapy with confirmed genotypic resistance to CLV (rtM204I mutation), and rescue therapy for CLV-resistance for more than 12 weeks with either ADV, CLV+ADV, LAM+ADV, or ETV. The rescue therapy in each case was decided prior to the study through discussions between patient and medical doctor. Hence, randomization was not performed.

Exclusion criteria were as follows: coinfection with hepatitis $\mathrm{C}$ virus, hepatitis D virus, or human immunodeficiency virus; clinical signs of alcoholism (i.e., weekly consumption over 140 g) or drug addiction; current treatment for malignant tumors; and current medication with drugs considered to have a direct effect on viral replication or the liver enzyme levels (e.g., steroids, immunosuppressive agents, or nonsteroidal anti-inflammatory agents). After enrollment of the cohort, the patients were prospectively followed-up over 48 weeks.

The study was approved by the Institutional Review Boards of each institution, and informed written consent was obtained from all study participants or their legal guardian, including for data sharing. The protocol conforms to the ethical guidelines of the Declaration of Helsinki.

\section{Study endpoints}

The following variable were evaluated at various time points throughout the study: (1) total bilirubin, albumin, aspartate transaminase, ALT, HBV DNA (quantitative real-time polymerase chain reaction), $\mathrm{HBeAg}$, and anti-HBe (antibody to HBeAg), at baseline, 12, 24, 36, and 48 weeks; (2) complete blood count, prothrombin time (PT) (international normalized ratio, INR), blood urea nitrogen, creatinine, $\mathrm{Na}, \mathrm{K}, \mathrm{Cl}$, and $\mathrm{P}$, at baseline, 24, and 48 weeks; (3) $\alpha$-fetoprotein, abdominal sonography, hepatitis B surface antigen (HBsAg), and anti-HBs (antibody to $\mathrm{HBsAg}$ ) at baseline and 48 weeks; and (4) monitoring of adverse events to medication at each outpatient clinic visit.

The primary study endpoint was proportion of patients with undetectable HBV DNA ( $<70 \mathrm{IU} / \mathrm{mL}$ ) at 48 weeks, which is defined as a virologic response. Secondary endpoints included undetectable HBV DNA at 12, 24, and 36 weeks; normalization of

Table 1. Comparison of Baseline Characteristics between the Treatment Groups

\begin{tabular}{|c|c|c|c|c|c|}
\hline \multirow{2}{*}{ Parameter } & \multicolumn{5}{|c|}{ Treatment group } \\
\hline & $\mathrm{ADV}$ & $\mathrm{CLV}+\mathrm{ADV}$ & $\mathrm{LAM}+\mathrm{ADV}$ & ETV & $\mathrm{p}$-value \\
\hline Patient & 12 & 21 & 34 & 40 & \\
\hline Age, yr & $48.9 \pm 16.2$ & $45.7 \pm 8.1$ & $48.1 \pm 12.7$ & $44.4 \pm 10.4$ & 0.468 \\
\hline Sex (M:F) & $3: 9$ & $16: 5$ & $22: 12$ & 29:11 & $0.014^{*}$ \\
\hline HBV DNA, $\log _{10}$ copies/mL & $6.19 \pm 0.79$ & $5.78 \pm 1.18$ & $5.47 \pm 1.65$ & $5.85 \pm 1.11$ & 0.372 \\
\hline HBeAg & 10 & 18 & 31 & 31 & 0.757 \\
\hline ALT, IU/L & $161.9 \pm 283.4$ & $151.6 \pm 331.0$ & $99.0 \pm 116.3$ & $74.7 \pm 92.8$ & 0.358 \\
\hline AST, IU/L & $87.3 \pm 71.3$ & $100.9 \pm 191.4$ & $101.2 \pm 137.1$ & $65.8 \pm 65.7$ & 0.598 \\
\hline Bilirubin, mg/dL & $0.71 \pm 0.24$ & $0.96 \pm 0.28$ & $0.83 \pm 0.45$ & $0.89 \pm 0.34$ & 0.286 \\
\hline Albumin, g/dL & $4.68 \pm 0.10$ & $4.41 \pm 0.21$ & $4.27 \pm 0.40$ & $4.39 \pm 0.26$ & $0.001^{*}$ \\
\hline Creatinine, $\mathrm{mg} / \mathrm{dL}$ & $0.79 \pm 0.21$ & $0.88 \pm 0.18$ & $0.86 \pm 0.23$ & $0.91 \pm 0.22$ & 0.491 \\
\hline PT, INR & $0.93 \pm 0.08$ & $0.98 \pm 0.08$ & $1.03 \pm 0.06$ & $1.09 \pm 0.17$ & $0.013^{*}$ \\
\hline Hemoglobin, g/dL & $14.2 \pm 1.3$ & $14.7 \pm 1.6$ & $15.1 \pm 1.7$ & $15.2 \pm 0.9$ & 0.306 \\
\hline Platelet, $10^{3} / \mu \mathrm{L}$ & $208.0 \pm 94.4$ & $230.4 \pm 51.5$ & $189.3 \pm 48.4$ & $179.0 \pm 52.0$ & $0.047^{*}$ \\
\hline AFP, ng/mL & $3.5 \pm 4.7$ & $2.0 \pm 1.0$ & $4.8 \pm 4.1$ & $5.2 \pm 10.5$ & 0.502 \\
\hline Duration of CLV therapy, mo & $18.2 \pm 5.6$ & $17.2 \pm 4.5$ & $20.0 \pm 6.5$ & $17.1 \pm 5.9$ & 0.374 \\
\hline
\end{tabular}

Data are presented as number or mean \pm SD.

ADV, adefovir; CLV, clevudine; LAM, lamivudine; ETV, entecavir; M, male; F, female; HBV DNA, hepatitis B virus DNA; HBeAg, hepatitis B antigen; ALT, alanine transaminase; AST, aspartate transaminase; PT, prothrombin time; INR, international normalized ratio; AFP, $\alpha$-fetoprotein. *Significant findings with $\mathrm{p}<0.05$. 
ALT, HBeAg loss, HBeAg seroconversion, and virologic or biochemical breakthroughs at $12,24,36$, and 48 weeks. The definitions of virologic breakthrough, biochemical breakthrough, primary nonresponse, and partial virologic response followed the European Association for the Study of the Liver (EASL) guidelines. $^{11}$

\section{Statistical analysis}

Patients who switched therapies or who were lost to followup within 24 weeks were excluded from the final analysis. Comparisons of categorical variables were performed with the chisquare test or the Fischer exact test, while analysis of variance (ANOVA) was used to compare continuous variables. A p-value $<0.05$ was considered statistically significant. Statistical analysis was performed with SPSS version 12 (SPSS Inc., Chicago, IL, USA) by a biomedical statistician (J.M.L.).

\section{RESULTS}

\section{Study population characteristics}

A total of 118 patients were enrolled in the study. Eleven patients were excluded from final analysis: two cases had switched therapies within 48 weeks (one had elevated creatine phosphokinase (CPK) and the other developed symptomatic myopathy), and nine cases were lost to follow-up within 24 weeks. The data from the remaining 107 patients were analyzed. Patients received either ADV ( $n=12), C L V+A D V(n=21), L A M+A D V(n=34)$, or ETV $(n=40)$ therapy for 48 weeks. Baseline characteristics of all patients are shown in Table 1; these did not differ between groups, with the exception of sex, serum albumin, PT (INR), and platelet counts $(p=0.014, p=0.001, p=0.013$, and $p=0.047$, respectively). These values were within the normal range in all groups, albeit the ETV group had the lowest platelet counts and the highest PT (INR), and the LAM+ADV group had the lowest albumin levels (Table 1). The HBV DNA level was highest in the ADV group compared to all other groups, but this did not reach statistical significance $(\mathrm{p}=0.372)$ (Table 1$)$.

\section{Virologic and biochemical responses}

The CLV+ADV group showed the greatest reduction in HBV DNA levels compared to all other groups $(p=0.004)$ (Fig. 1), and this group had the lowest HBV DNA level of all groups $(\mathrm{p}<0.0001)$ (Table 2) at week 48. Mean ALT levels at weeks 12, 24, 36, and 48 did not differ between groups (Table 3, Fig. 2); this was also the case for the proportion of patients achieving ALT normalization at week 48 (Table 4). However, the $\mathrm{CLV}+\mathrm{ADV}$ group displayed the highest proportion of patients with undetectable HBV DNA at week 48 compared to all other groups ( $\mathrm{p}=0.002$ ) (Table 4). The proportion of patients achieving $\mathrm{HBeAg}$ loss or seroconversion at week 48 did not differ between groups (Table 4).

\section{Primary nonresponse, partial virologic response, and virologic and biochemical breakthrough}

Primary nonresponse and partial virologic response during rescue therapy in patients with CLV-resistance were highest in the ADV group and lowest in the CLV+ADV group. The propor-

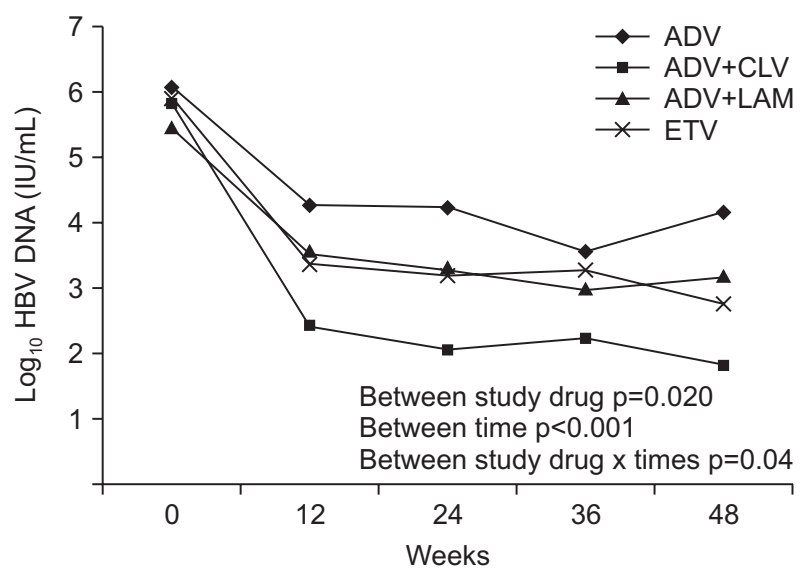

Fig. 1. Serial changes in hepatitis B virus (HBV) DNA values in patients with clevudine-resistant chronic hepatitis B. Rescue therapy groups: ADV, adefovir; CLV, clevudine; LAM, lamivudine; ETV, entecavir.

Table 2. Mean HBV DNA Levels according to Time Points in the Four Different Treatment Groups $\left(\log _{10}\right.$ copies $\left./ \mathrm{mL}\right)$

\begin{tabular}{|c|c|c|c|c|c|c|}
\hline \multirow{2}{*}{ Treatment group } & \multicolumn{5}{|c|}{ Time, wk } & \multirow{2}{*}{$\mathrm{p}$-value } \\
\hline & 0 & 12 & 24 & 36 & 48 & \\
\hline $\mathrm{ADV}$ & $6.19 \pm 0.79$ & $4.54 \pm 0.85$ & $4.63 \pm 0.76$ & $3.19 \pm 1.25$ & $4.55 \pm 0.84$ & $<0.001^{*}$ \\
\hline $\mathrm{CLV}+\mathrm{ADV}$ & $5.78 \pm 1.18$ & $2.60 \pm 1.16$ & $2.57 \pm 1.34$ & $2.48 \pm 1.22$ & $1.94 \pm 0.88$ & $<0.001^{*}$ \\
\hline $\mathrm{LAM}+\mathrm{ADV}$ & $5.47 \pm 1.65$ & $3.44 \pm 1.26$ & $3.20 \pm 1.43$ & $3.21 \pm 1.51$ & $3.35 \pm 1.43$ & $<0.001^{*}$ \\
\hline ETV & $5.85 \pm 1.11$ & $3.42 \pm 1.57$ & $3.28 \pm 1.37$ & $3.57 \pm 1.51$ & $2.97 \pm 1.44$ & $<0.001^{*}$ \\
\hline $\mathrm{p}$-value & 0.372 & $0.003^{*}$ & $0.002^{*}$ & $0.026^{*}$ & $<0.0001^{*}$ & \\
\hline
\end{tabular}

Data are presented as mean \pm SD.

ADV, adefovir; CLV, clevudine; LAM, lamivudine; ETV, entecavir.

*The following comparisons were statistically significant within each column, with $p<0.05$ : CLV+ADV vs LAM+ADV and CLV+ADV vs ETV. Significant findings within each column or row. 
tions of patients achieving primary nonresponse in each group were as follows: $\operatorname{ADV}(3 / 12,25.0 \%)$; CLV+ADV (0/21, 0\%); $\mathrm{LAM}+\mathrm{ADV}(2 / 34,5.9 \%)$; and ETV (1/40, 2.5\%). Partial virologic responses were: ADV group (8/12, 66.6\%), CLV+ADV group (6/21, 28.6\%), LAM+ADV group (16/34, 47.1\%), and ETV group (18/40, 45.0\%).

At 48 weeks, the proportion of patients with virologic breakthrough tended to be lower in the CLV+ADV group, but differ-

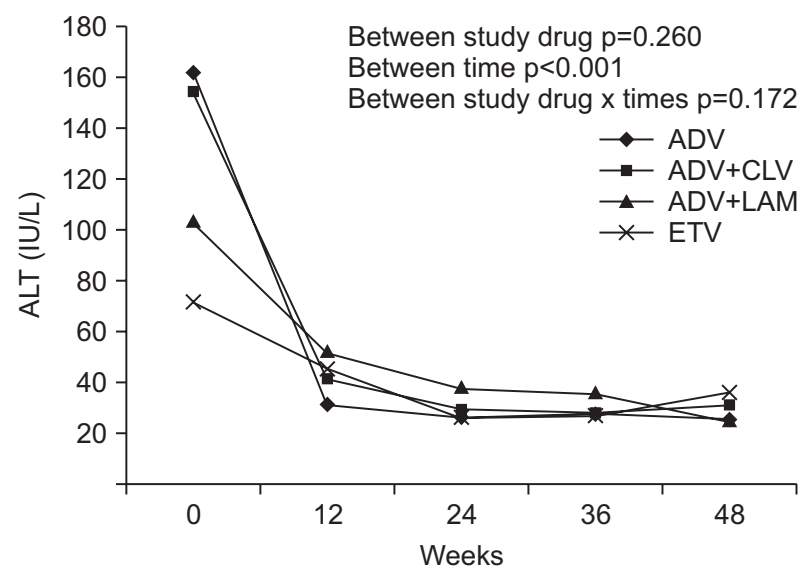

Fig. 2. Serial changes in alanine transaminase (ALT) values in patients with clevudine-resistant chronic hepatitis B. Rescue therapy groups: ADV, adefovir; CLV, clevudine; LAM, lamivudine; ETV, entecavir. ences between groups did not reach statistical significance (Table 4). In case of virologic breakthrough, therapies were switched to ETV+ADV combination in most of cases. Biochemical breakthrough rate did not differ between groups; one patient in the $\mathrm{ADV}$ group, two in the CLV+ADV group, one in the $\mathrm{LAM}+\mathrm{ADV}$ group, and three in the ETV group showed an increase in ALT values above upper limit of normal.

\section{Adverse events}

Elevation of CPK ( $>1,000 \mathrm{IU} / \mathrm{mL})$ was observed in three patients: two from CLV+ADV and one from LAM+ADV group. Only one patient in CLV group developed muscle weakness. Increase of serum creatinine $(>1.5 \mathrm{mg} / \mathrm{dL})$ was noted in one patient in CLV+ADV group. Hepatocellular carcinoma was diagnosed in one patient in LAM+ADV group during study period.

\section{Predictive factors associated with virologic response during 48 weeks of rescue therapy for clevudine-resistant patients}

The univariate analysis showed that rescue therapy regimen (CLV+ADV vs other drugs) and undetectable HBV DNA at 12and 24-week were predictive factors of undetectable HBV DNA at 48 weeks (Table 5). The multivariate analysis based on these data showed that therapeutic drugs (CLV+ADV) and undetectable HBV DNA at 12 weeks were predictive factors related to the 48 -week virologic response (Table 6). When delaying the time for prediction of virologic response till 24 weeks, undetectable HBV DNA at 24 weeks was the sole factor (Table 6).

Table 3. Mean ALT Levels according to Time Points in the Four Different Treatment Groups (IU/L)

\begin{tabular}{|c|c|c|c|c|c|c|}
\hline \multirow{2}{*}{ Treatment group } & \multicolumn{5}{|c|}{ Time, wk } & \multirow{2}{*}{ p-value } \\
\hline & 0 & 12 & 24 & 36 & 48 & \\
\hline $\mathrm{ADV}$ & $161.9 \pm 283.4$ & $31.4 \pm 9.3$ & $28.5 \pm 8.8$ & $28.3 \pm 8.5$ & $23.7 \pm 9.3$ & $<0.001^{*}$ \\
\hline $\mathrm{CLV}+\mathrm{ADV}$ & $151.6 \pm 331.0$ & $43.8 \pm 30.4$ & $31.2 \pm 17.7$ & $34.4 \pm 28.6$ & $31.9 \pm 20.9$ & $<0.001^{*}$ \\
\hline $\mathrm{LAM}+\mathrm{ADV}$ & $99.0 \pm 116.3$ & $52.5 \pm 44.6$ & $38.3 \pm 26.4$ & $37.0 \pm 33.9$ & $25.2 \pm 9.7$ & $<0.001^{*}$ \\
\hline ETV & $74.7 \pm 92.8$ & $44.9 \pm 64.5$ & $25.6 \pm 13.4$ & $27.8 \pm 22.6$ & $37.5 \pm 26.6$ & $<0.001^{*}$ \\
\hline $\mathrm{p}$-value & 0.358 & 0.698 & 0.060 & 0.562 & 0.074 & \\
\hline
\end{tabular}

Data are presented as the mean \pm SD.

ALT, alanine aminotransferase; ADV, adefovir; CLV, clevudine; LAM, lamivudine; ETV, entecavir.

*Significant differences within each row.

Table 4. Proportion of Patients according to Treatment Responses in the Four Different Groups at Week 48

\begin{tabular}{|c|c|c|c|c|c|}
\hline & $\mathrm{ADV}$ & $\mathrm{ADV}+\mathrm{CLV}$ & $\mathrm{ADV}+\mathrm{LMV}$ & ETV & p-value \\
\hline HBV DNA <70 IU/mL & $0 / 12(0)$ & $12 / 21(57.1)$ & $7 / 34(21.2)$ & $11 / 40(27.5)$ & $0.002^{*}$ \\
\hline ALT normalization & $11 / 12(91.7)$ & $17 / 21(81.0)$ & $29 / 34(85.3)$ & $31 / 40(77.5)$ & 0.662 \\
\hline HBeAg loss or seroconversion & $2 / 10(20.0)$ & $2 / 18(11.1)$ & $3 / 31(9.7)$ & $3 / 31(9.7)$ & 0.838 \\
\hline Virologic breakthrough & $4 / 12(33.3)$ & 4/21 (19.0) & $13 / 34(38.2)$ & $18 / 40(45.0)$ & 0.250 \\
\hline
\end{tabular}

Data are presented as number/total number $(\%)$.

ADV, adefovir; CLV, clevudine; LAM, lamivudine; ETV, entecavir; n, number of patients with each response/number of patients who started the corresponding rescue therapy; HBV, hepatitis B virus; ALT, alanine transaminase; HBeAg, hepatitis B e antigen.

*Significant differences with $\mathrm{p}<0.05$. 
Table 5. Univariate Analysis of Baseline and On-Treatment Factors Related to the Virologic Response in Patients with Clevudine-Resistant Chronic Hepatitis B

\begin{tabular}{|c|c|c|}
\hline & OR & $95 \% \mathrm{CI}$ \\
\hline \multicolumn{3}{|l|}{ Drug } \\
\hline $\mathrm{ADV}$ & - & - \\
\hline $\mathrm{CLV}+\mathrm{ADV}$ & 5.600 & $1.220-25.750$ \\
\hline $\mathrm{LAM}+\mathrm{ADV}$ & 0.660 & $0.200-2.170$ \\
\hline ETV & 1 & - \\
\hline \multicolumn{3}{|l|}{ Sex } \\
\hline Male & 2.400 & $0.820-6.990$ \\
\hline Female & 1 & \\
\hline \multicolumn{3}{|l|}{$\mathrm{HBeAg}$} \\
\hline Positive & 0.580 & $0.120-2.830$ \\
\hline Negative & 1 & - \\
\hline CLV treatment duration & 1.020 & $0.920-1.130$ \\
\hline Age & 1 & $0.960-1.041$ \\
\hline AST & 1.002 & $1-1.008$ \\
\hline ALT & 1.003 & $1-1.006$ \\
\hline Total bilirubin & 2.392 & $0.692-8.270$ \\
\hline Albumin & 0.651 & $0.149-2.836$ \\
\hline Log HBV DNA & 1.039 & $0.704-1.535$ \\
\hline $\mathrm{Cr}$ & 2.255 & $0.205-24.828$ \\
\hline Platelets & 0.999 & 0.989-1.009 \\
\hline AFP & 1.032 & $0.962-1.107$ \\
\hline \multicolumn{3}{|l|}{ Sono } \\
\hline No LC & 1.650 & $0.457-5.964$ \\
\hline LC & 1 & - \\
\hline \multicolumn{3}{|c|}{ HBV DNA at week $12^{*}, \mathrm{IU} / \mathrm{mL}$} \\
\hline$<70$ & 6.462 & $1.869-22.345$ \\
\hline$>70$ & 1 & - \\
\hline \multicolumn{3}{|c|}{ HBV DNA at week $24^{*}, \mathrm{IU} / \mathrm{mL}$} \\
\hline$<70$ & 6.333 & $1.955-20.517$ \\
\hline$>70$ & 1 & - \\
\hline
\end{tabular}

OR, odds ratio; CI, confidence interval; ADV, adefovir; CLV, clevudine; LAM, lamivudine; ETV, entecavir; HBeAg, hepatitis B e antigen; AST, aspartate transaminase; ALT, alanine transaminase; HBV, hepatitis B virus; $\mathrm{Cr}$, creatinine; AFP, $\alpha$-fetoprotein; Sono, abdominal ultrasonography; LC, liver cirrhosis.

*All parameters are baseline factors except HBV DNA at week 12 and 24.

\section{DISCUSSION}

Currently, CLV is not commonly used for initial antiviral treatment of $\mathrm{CHB}$ patients for several reasons including relatively high incidence of antiviral resistance. ${ }^{5-7}$ Nevertheless, CLV is being prescribed in Korea and in Philippines albeit the frequency is decreasing. So far, patients with CLV resistance have been treated with various regimens, but no report has been
Table 6. Multivariate Analysis of Baseline and On-Treatment Factors Related to the Virologic Response in Patients with ClevudineResistant Chronic Hepatitis B

\begin{tabular}{|c|c|c|c|c|}
\hline & \multicolumn{2}{|c|}{ Model I } & \multicolumn{2}{|c|}{ Model II } \\
\hline & $\mathrm{OR}$ & $95 \% \mathrm{CI}$ & $\mathrm{OR}$ & $95 \% \mathrm{CI}$ \\
\hline \multicolumn{5}{|l|}{ Drug } \\
\hline $\mathrm{ADV}$ & - & - & - & - \\
\hline $\mathrm{CLV}+\mathrm{ADV}$ & 8.029 & $1.349-47.775$ & 3.814 & $0.712-20.433$ \\
\hline $\mathrm{LAM}+\mathrm{ADV}$ & 0.966 & $0.227-4.109$ & 0.522 & $0.131-2.074$ \\
\hline ETV & 1 & - & 1 & - \\
\hline \multicolumn{5}{|c|}{ HBV DNA at week $12^{*}, \mathrm{IU} / \mathrm{mL}$} \\
\hline$<70$ & 5.253 & $1.145-24.105$ & & \\
\hline$>70$ & 1 & - & & \\
\hline \multicolumn{5}{|c|}{ HBV DNA at week $24^{*}, \mathrm{IU} / \mathrm{mL}$} \\
\hline$<70$ & & & 4.307 & $1.121-16.550$ \\
\hline$>70$ & & & 1 & - \\
\hline
\end{tabular}

OR, odds ratio; CI, confidence interval; ADV, adefovir; CLV, clevudine; LAM, lamivudine; ETV, entecavir; HBV, hepatitis B virus.

published regarding management of CLV resistance.

This study compared the antiviral effect of rescue therapies in CLV-resistant patients divided into four groups according to the regimens: $\mathrm{ADV}, \mathrm{CLV}+\mathrm{ADV}$, $\mathrm{LAM}+\mathrm{ADV}$, and ETV. No differences were observed in the biochemical response rates among the groups, but significant differences were found in the virological response rates. The CLV+ADV group displayed the highest virologic response whereas the ADV group displayed the lowest virologic response. The $\mathrm{LAM}+\mathrm{ADV}$ group had similar virologic response rate to the ETV group. As there are no reports on rescue therapy for CLV-resistance, the current recommendation is to use the same method as for treatment of LAM-resistance., ${ }^{9,12}$ However, according to our data, the LAM+ADV combination therapy, which is considered a preferred therapy for LAMresistant $\mathrm{CHB}$ patients because it induces less drug resistance and high viral response, did not show a higher viral suppressive effect than the monotherapies considering the mean HBV DNA levels. In terms of virologic response rates, $\mathrm{LAM}+\mathrm{ADV}$ combination therapy for 1 year showed undetectable HBV DNA rates of $40 \%$ to $70 \%$ in previous studies for LAM-resistant CHB patients. ${ }^{13,14}$ However, in our study, this group showed low virologic response $(21.2 \%$ of patients with undetectable HBV DNA), whilst 57.1\% patients in the CLV+ADV combination therapy group showed undetectable HBV DNA. In addition, the $\mathrm{LAM}+\mathrm{ADV}$ group showed similar rates of virologic response rate compared to the monotherapy groups $(p=0.121$, data not shown). It is thought that $\mathrm{LAM}+\mathrm{ADV}$ combination is not very effective for suppressing CLV-resistant HBV. Therefore, the LAM+ADV combination should not be considered the first recommendation as a rescue therapy for CLV-resistant CHB patients. 
In relation to the treatment effect of the other rescue therapies investigated in this study, ETV monotherapy showed similar rates of undetectable HBV DNA and ALT normalization to those reported in previous studies in LAM-resistant patients with $\mathrm{CHB} .{ }^{15-17}$ However, the mean HBV DNA levels were higher than $\mathrm{CLV}+\mathrm{ADV}$ combination therapy during treatment. The ADV monotherapy showed lower antiviral effect than in previous studies. ${ }^{15,18,19}$ In particular, none of the ADV group patients showed a virologic response at the 48 weeks of treatment. In the ADV group, $25 \%$ of patients showed a primary nonresponse and $66.6 \%$ showed a partial virologic response and, therefore, $91.6 \%$ of patients did not achieve virologic response. Only one case showed a virologic response $(<70 \mathrm{IU} / \mathrm{mL})$ after 36 weeks of treatment but experienced virologic breakthrough at 48 weeks with a substantial increase in viral load (3240 IU/mL). These findings demonstrate that ADV monotherapy is not the proper option for the treatment of CLV-resistant CHB.

In this study, only CLV+ADV combination therapy showed an acceptable virologic response rate of 57.1\%. The reduction in HBV DNA in the CLV+ADV group was significantly greater than in all other groups and virologic response rate was significantly higher after treatment for 48 weeks. In addition, we evaluated the predictive factors for 48 week-virologic response, and it was found that CLV+ADV therapy and undetectable HBV DNA at 12 weeks were the most significant factors. However, two patients developed increase of CPK, and one of them experienced muscle weakness. Muscle-related problems have been reported in $\mathrm{CHB}$ patients receiving CLV previously. ${ }^{20-23}$ Incidence of the myopathy related to CLV varied $2.9 \%$ to $14.6 \%$, and it became a major drawback of CLV in clinical use. ${ }^{20-23}$ Especially, long term administration of CLV could be the one of the risk factor for its development. ${ }^{21,23}$ This prevents us from recommending CLV+ADV combination for CLV-resistant CHB routinely. In addition, ADV has potential risk of nephrotoxicity, and one patient of our cohort displayed increase of serum creatinine. ${ }^{14,24}$ Hence CLV+ADV combination therapy can only be recommend with caution of these adverse events.

Currently, TDF has been approved for patients with chronic $\mathrm{HBV}$ infection, and known to be more efficacious than ADV. ${ }^{25}$ TDF was tested for CHB resistant to $\mathrm{LAM}^{26} \mathrm{ADV}^{27-29}$ or ETV, ${ }^{30}$ and patients with multiple treatment failures, ${ }^{28,29,31}$ and TDF monotherapy was as effective as combination therapy in these population. ${ }^{26,28,30}$ As TDF is expected superior to $\mathrm{LAM}+\mathrm{ADV}$ combination in LAM-resistant $\mathrm{CHB},{ }^{32}$ there is high possibility of favorable response in CLV-resistant CHB, probably even better than CLV+ADV. Unfortunately, we did not have chance to evaluate the efficacy of TDF in patients with CLV resistance as TDF was not available during the study period in Korea. As TDF is still not available in several Asian countries, our data will provide important information for choosing rescue therapies in CLV resistant CHB.

This is the first report on the effect of rescue therapies for
CLV-resistant CHB patients. However, this study had several limitations: (1) it was a nonrandomized study as patients were recruited in the cohort after starting the rescue therapies; (2) it did not include TDF-based therapies; (3) the sample size in each rescue therapy group was relatively small; and (4) genotypic resistance was not confirmed in patients with viral breakthrough during 48 weeks of the rescue therapies. Therefore, further research with a larger sample size and covering the issues raised above is necessary to determine the best option for CLV-resistant CHB patients.

In conclusion, rescue therapies for CLV-resistant CHB patients (ADV, CLV+ADV, LAM+ADV, and ETV) showed similar biochemical response, $\mathrm{HBeAg}$ seroconversion rate, and virologic breakthrough rate. CLV+ADV combination therapy showed an improved virologic response. Several options which have used for rescue therapy of LAM-resistant CHB patients (ADV, $\mathrm{LAM}+\mathrm{ADV}$, and ETV) were not effective in inhibiting viral replication in CLV-resistant CHB patients.

\section{CONFLICTS OF INTEREST}

No potential conflict of interest relevant to this article was reported.

\section{ACKNOWLEDGEMENTS}

This study was funded by Korean Association for the Study of the Liver.

\section{REFERENCES}

1. Lee HS, Chung YH, Lee K, et al. A 12-week clevudine therapy showed potent and durable antiviral activity in HBeAg-positive chronic hepatitis B. Hepatology 2006;43:982-988.

2. Lee KS, Byun KS, Chung YH, et al. Clevudine therapy for 24 weeks further reduced serum hepatitis B virus DNA levels and increased ALT normalization rates without emergence of viral breakthrough than 12 weeks of clevudine therapy. Intervirology 2007;50:296302.

3. Yoo BC, Kim JH, Chung YH, et al. Twenty-four-week clevudine therapy showed potent and sustained antiviral activity in HBeAgpositive chronic hepatitis B. Hepatology 2007;45:1172-1178.

4. Yoo BC, Kim JH, Kim TH, et al. Clevudine is highly efficacious in hepatitis B e antigen-negative chronic hepatitis B with durable off-therapy viral suppression. Hepatology 2007;46:1041-1048.

5. Kim MH, Kim KA, Lee JS, et al. Efficacy of 48-week clevudine therapy for chronic hepatitis B. Korean J Hepatol 2009;15:331-337.

6. Ko SY, Kwon SY, Choe WH, Kim BK, Kim KH, Lee CH. Clinical and virological responses to clevudine therapy in chronic hepatitis B patients: results at 1 year of an open-labelled prospective study. Antivir Ther 2009;14:585-590.

7. Lee HJ, Eun JR, Lee CH, et al. Long-term clevudine therapy in 
nucleos(t)ide-naïve and lamivudine-experienced patients with hepatitis B virus-related chronic liver diseases. Korean J Hepatol 2009;15:179-192.

8. Korean Association for the Study of the Liver. KASL clinical practice guidelines: management of chronic hepatitis B. Clin Mol Hepatol 2012;18:109-162.

9. Lee KS, Kim DJ; Korean Association for the Study of the Liver Guideline Committee. Management of chronic hepatitis B. Korean J Hepatol 2007;13:447-488.

10. Yim HJ, Hwang SG. Options for the management of antiviral resistance during hepatitis B therapy: reflections on battles over a decade. Clin Mol Hepatol 2013;19:195-209.

11. European Association for the Study of the Liver. EASL clinical practice guidelines: management of chronic hepatitis B virus infection. J Hepatol 2012;57:167-185.

12. Lee KS. Clevudine therapy in patients with chronic hepatitis B. Korean J Hepatol 2009;15:119-121.

13. Rapti I, Dimou E, Mitsoula P, Hadziyannis SJ. Adding-on versus switching-to adefovir therapy in lamivudine-resistant HBeAgnegative chronic hepatitis B. Hepatology 2007;45:307-313.

14. Yim HJ, Seo YS, Yoon EL, et al. Adding adefovir vs. switching to entecavir for lamivudine-resistant chronic hepatitis B (ACE study): a 2-year follow-up randomized controlled trial. Liver Int 2013;33:244-254.

15. Kim HJ, Park JH, Park DI, et al. Rescue therapy for lamivudine-resistant chronic hepatitis B: comparison between entecavir $1.0 \mathrm{mg}$ monotherapy, adefovir monotherapy and adefovir add-on lamivudine combination therapy. J Gastroenterol Hepatol 2010;25:13741380.

16. Ryu HJ, Lee JM, Ahn SH, et al. Efficacy of adefovir add-on lamivudine rescue therapy compared with switching to entecavir monotherapy in patients with lamivudine-resistant chronic hepatitis B. J Med Virol 2010;82:1835-1842.

17. Suzuki F, Toyoda J, Katano Y, et al. Efficacy and safety of entecavir in lamivudine-refractory patients with chronic hepatitis B: randomized controlled trial in Japanese patients. J Gastroenterol Hepatol 2008;23:1320-1326.

18. Dai CY, Chuang WL, Hsieh MY, et al. Adefovir dipivoxil treatment of lamivudine-resistant chronic hepatitis B. Antiviral Res 2007;75:146-151.

19. Peters MG, Hann Hw, Martin P, et al. Adefovir dipivoxil alone or in combination with lamivudine in patients with lamivudineresistant chronic hepatitis B. Gastroenterology 2004;126:91-101.

20. Kim BK, Oh J, Kwon SY, et al. Clevudine myopathy in patients with chronic hepatitis B. J Hepatol 2009;51:829-834.

21. Seok JI, Lee DK, Lee CH, et al. Long-term therapy with clevudine for chronic hepatitis B can be associated with myopathy characterized by depletion of mitochondrial DNA. Hepatology 2009;49:2080-2086.

22. Tak WY, Park SY, Cho CM, et al. Clinical, biochemical, and pathological characteristics of clevudine-associated myopathy. J Hepatol 2010;53:261-266.

23. Yoon EL, Yim HJ, Lee HJ, et al. Comparison of clevudine and entecavir for treatment-naïve patients with chronic hepatitis B virus infection: two-year follow-up data. J Clin Gastroenterol 2011;45: 893-899.

24. Fung SK, Lok AS. Drug insight: nucleoside and nucleotide analog inhibitors for hepatitis B. Nat Clin Pract Gastroenterol Hepatol 2004;1:90-97.

25. Marcellin P, Heathcote EJ, Buti M, et al. Tenofovir disoproxil fumarate versus adefovir dipivoxil for chronic hepatitis B. N Engl J Med 2008;359:2442-2455.

26. Fung S, Kwan P, Fabri M, et al. Randomized comparison of tenofovir disoproxil fumarate vs emtricitabine and tenofovir disoproxil fumarate in patients with lamivudine-resistant chronic hepatitis B. Gastroenterology 2014;146:980-988.

27. Berg T, Marcellin P, Zoulim F, et al. Tenofovir is effective alone or with emtricitabine in adefovir-treated patients with chronichepatitis B virus infection. Gastroenterology 2010;139:1207-1217.

28. Lim YS, Yoo BC, Byun KS, et al. Tenofovir monotherapy versus tenofovir and entecavir combination therapy in adefovir-resistant chronic hepatitis B patients with multiple drug failure: results of a randomised trial. Gut 2016;65:1042-1051.

29. Patterson SJ, George J, Strasser SI, et al. Tenofovir disoproxil fumarate rescue therapy following failure of both lamivudine and adefovir dipivoxil in chronic hepatitis B. Gut 2011;60:247-254.

30. Lim YS, Byun KS, Yoo BC, et al. Tenofovir monotherapy versus tenofovir and entecavir combination therapy in patients with entecavir-resistant chronic hepatitis B with multiple drug failure: results of a randomised trial. Gut 2016;65:852-860.

31. Kim HJ, Cho JY, Kim YJ, et al. Long-term efficacy of tenofovir disoproxil fumarate therapy after multiple nucleos(t)ide analogue failure in chronic hepatitis B patients. Korean J Intern Med 2015; 30:32-41.

32. Yang DH, Xie YJ, Zhao NF, Pan HY, Li MW, Huang HJ. Tenofovir disoproxil fumarate is superior to lamivudine plus adefovir in lamivudine-resistant chronic hepatitis B patients. World J Gastroenterol 2015;21:2746-2753. 